This item was submitted to Loughborough's Research Repository by the author.

Items in Figshare are protected by copyright, with all rights reserved, unless otherwise indicated.

\title{
Female counter-adaptations to rape
}

\section{PLEASE CITE THE PUBLISHED VERSION}

https://doi.org/10.1007/978-3-319-16999-6

\section{PUBLISHER}

(C) Springer

\section{VERSION}

AM (Accepted Manuscript)

\section{PUBLISHER STATEMENT}

This work is made available according to the conditions of the Creative Commons Attribution-NonCommercialNoDerivatives 4.0 International (CC BY-NC-ND 4.0) licence. Full details of this licence are available at: https://creativecommons.org/licenses/by-nc-nd/4.0/

\section{LICENCE}

CC BY-NC-ND 4.0

\section{REPOSITORY RECORD}

Ryder, Hannah L., Nicole Williams, John Maltby, and Heather Flowe. 2017. "Female Counter-adaptations to Rape". Loughborough University. https://hdl.handle.net/2134/23806. 


\section{Book Chapter- Female Counter-Adaptations to Rape}

\section{Introduction and definition}

Rape is defined as "penetration, no matter how slight, of the vagina or anus with any body part or object, or oral penetration by a sex organ of another person, without the consent of the victim" (The United States Department of Justice, 2012). In the US, an estimated one in six women will be raped in their lifetime, with $29 \%$ of victims being between the ages of 18 to 24 years (Tjaden \& Thoennes, 2006). However, it is likely these figures only represent a small number of rape victims, as rape is seldomly reported to the police. Approximately $15 \%$ of victims are estimated to report sexual violence to the police (Office for National Statistics, 2013). Low reporting may stem from societal misconceptions surrounding rape, particularly around victim blaming (e.g., Grubb \& Turner, 2012). What is more, rape often has serious psychological consequences for victims. For instance, victims often sustain Post Traumatic Stress Disorder (PTSD) following rape, with PTSD prevalence rates ranging from 37-57\% (Kilpatrick, Edmunds \& Seymour, 1992; Resnick, Kilpatrick, Dansky, Saunders \& Best, 1993).

This chapter reviews the literature on evolutionary explanations of rape. In particular, it will discuss research that has investigated whether women have rape counter-adaptations. Rape counteradaptations entail specialized mechanisms that reduce women's risk of male sexual coercion. Our discussion will be necessarily restricted to rape perpetrated on women by men. Although women can perpetrate rape and men can be the victims of rape, most rapes are perpetrated by men against women (Office for National Statistics, 2013). Accordingly, evolutionary explanations of rape have been concerned with accounting for male-perpetrated rapes against females.

\section{Costs of rape}

The evolutionary framework assumes that animals strive to attain two fundamental goals: survive and reproduce offspring. In women, successful reproduction is considered to be passing on the strongest genes and resources that will increase the chances of survival of the species. During peak fertility, women aim to attract the highest quality mate to achieve this. Successful reproduction for males involves the quantity of their offspring, with less importance being placed on their quality (Bateman, 1948; Trivers, 1972). In order to survive, some psychologists propose that humans weigh up the costs and benefits of putting themselves in certain situations, which could prove fruitful, in terms of achieving resources to benefit fitness, such as meeting mates, but could also pose risks in terms of encountering aggressive mates, for example. For the purposes of this chapter, benefits refer to outcomes of a positive sexual encounter (e.g., increased chances of successful reproduction) whilst costs refer to the consequences of a negative sexual encounter (e.g. decreased chances of successful reproduction). Rape, therefore, is a high cost due to the reduced chances of a successful and wanted reproduction (McKibbin, 2014).

Perhaps one of the most obvious costs of rape is the psychological pain felt by the victim. With regards to reproductive fitness specifically, however, pregnancy arising from rape is considered to be one of the highest costs of rape. Pregnancy reduces a woman's reproductive fitness significantly because she must carry and raise offspring with a mate not of her choosing, thereby limiting her reproductive resources. It is argued that "perhaps the most important priority for many female animals in their heterosexual interactions is the maintenance of [mate] choice” (Wilson et al. 1997, p.443). Rape circumvents female mate choice, and so, according to the evolutionary framework, it is particularly costly with regard to unwanted conception. 
Evolutionary models emphasize the differential investment that women and men make in reproduction. Relative to men, women have fewer sex cells and they generally provide more time and energy to raising offspring following conception. Therefore, it detrimental to a women's reproductive fitness if pregnancy occurs with an undesirable mate and under conditions in which valuable resources to support the offspring are unavailable. Parental investment theory proposes that investing in offspring increases the offspring's chance of survival while limiting other reproductive opportunities (Bateman, 1948; Trivers, 1972). One hypothesis that can be derived from this is that women must take care to choose a mate who will invest time and provide valuable resources with respect to offspring. Supporting this hypothesis, women are more fearful of stranger rape despite it being much less common than acquaintance rape (Thornhill \& Thornhill, 1990b). It has been argued that fear is lower in acquaintance rape because, arguably, relative to a stranger, an acquaintance is more likely to provide resources to an offspring of rape, which reduces the cost for a woman. Furthermore, research has shown that psychological pain varies across victims, with women who are married reporting more psychological pain than victims who are single (Thornhill \& Palmer, 2000). It has been posited that married women suffer more pain because of the potential for abandonment and a loss of resources from their spouse if they are perceived as adulterous. Furthermore, it has also been found that women of a reproductive age who would face greater costs to their future reproductive fitness report more psychological pain (Thornhill \& Thornhill, 1983; 1990a: Thornhill \& Palmer, 2000). Women of reproductive age are more fearful of being assaulted and raped, than older women, who in turn are more fearful of a burglary. Fear seems to contribute to the experience of psychological pain (Pawson \& Banks, 1993), which might account for some of the variation in psychological pain in response to rape. Thus, although pregnancy is one of the most widely researched costs of rape, it is important to recognise it is not the only cost for victims.

Due to the high cost of rape, it has been theorised that women have evolved counter-adaptions in order to reduce the likelihood of rape occurrence (e.g., Thornhill \& Palmer, 2000). Adaptations are evolutionary solutions to environmental challenges faced by our ancestors (Ridley, 1987, cited in Thornhill \& Palmer, 2000; Williams, 1966; Symons, 1979). Adaptive traits are selected through natural and sexual selection (e.g., Darwin, 1859, as cited in Confer, Easton, Fleischman, Goetz, Lewis, Perilloux \& Buss, 2010). That is, traits that increase 'fitness', through successful reproduction and survival, are reproduced in future generations. Thus, adaptations work to increase the chance of reproduction and/or survival. Psychological pain, in particular, has been theorised to serve an evolutionary function in regards to the adaptation of behaviours and cognitions in order to overcome problems. Thornhill and Thornhill (1989; 1990a, 1990b, 1990c, 1991) proposed that, in regards to rape, psychological pain has an adaptive benefit, focusing a women's attention on circumstances that may have led to the rape occurring. This would then allow women to avoid a similar situation in the future, with this mechanism being passed on to future generations to allow offspring to avoid rape without ever directly experiencing the psychological and physical pain of rape.

In view of the high costs of rape, it has been proposed that women evolved adaptations to counter rape. These are referred to as counter-adaptations, because, quite controversially, some evolutionary psychologists have hypothesized that rape by a male onto a female has evolved as an adaptive reproductive tactic to spread their genetic make up to a high degree (see Thornhill \& Palmer, 2000). Thus, a rape avoidance adaptation in women has evolved to counter to this male adaptation. We will now review briefly the theory and some of the evidence behind the hypothesis that rape is an adaptive male behaviour. However, the focus of this chapter will be on reviewing the theory and evidence behind the hypothesis that women have evolved counteradaptations to rape.

\section{Is Rape Evolutionary?}


It has generally been thought that rape by a male of a female evolved as a tactic to allow males to spread their genetic make up to a high degree (see Thornhill \& Palmer, 2000). However, it is important to consider that rape may be a by-product of other evolved male traits, such as a greater desire for sexual variety, a higher sex drive, or aggressiveness (Symons, 1979).

Although rape may be a byproduct of other evolutionary traits, it is also hypothesised that rape has evolved to increase the chances of successful genetic reproduction in males who cannot receive legitimate consensual intercourse from desirable female partners (see Thornhill \& Palmer, 2000). It is argued that males who do not have access to desirable attributes for both females and potential offspring are more likely to rape than those who do. This concept has been shown in male scorpion flies, whereby males who lack the resources (i.e., nuptial gifts) to be selected as mates, have been shown to attempt forced copulation, Thornhill, 1980, 1984; Thornhill \& Sauer 1991). In humans, criminal statistics suggest that men from low socioeconomic areas are more likely to rape, as discussed by Thornhill and Thornhill (1983). High status men are deemed less likely to rape as they are considered to have access to potential partners who would freely give sexual consent, whereas 'low status' men may not have this (e.g., see Thornhill \& Thornhill, 1983; Vaughn, 2002). Eisenhower (1969) studied the likelihood of rape occurring in various areas of residence within a city and found that in rich suburbs, females faced a 1 in 10,000 chance of being raped, whilst in the poorer inner-city there was a 1 in 77 chance of being raped. Alternatively, Thornhill and Thornhill (1983) argue that it may be in certain societies, such as in the United States, wealthier men are less likely to be caught or are in a better position to gain legal help to either have a case over turned or to settle out of court. It may also be the case that men who are considered to be 'upstanding citizens' or are of a higher class will not be tried as harshly alongside having access to the best legal assistance. Therefore, it may not be the case that men from low socioeconomic backgrounds are more likely to rape than their higher socioeconomic counterparts, but rather, that they are overrepresented in prison statistics because they have inadequate access to legal assistance. It is, therefore, difficult to fully know whether there is a relationship between socioeconomic level and the propensity to rape, as the representation of low status males in rape data is likely to be inflated.

Analysis of pregnancy rates after rape has suggested that the per-incident rate of conception after rape is higher than consensual pregnancy rates after controlling for birth control use, suggesting that rape has evolved to allow males to spread their genetics (Gottschall \& Gottschall, 2003). In this study, data was collected from the National Violence Against Women survey, involving a randomdigit dialing sample of households in the United States. Participants were considered to be rape victims if they answered yes to the question "Regardless of how long ago it happened, has a man or boy ever made you have sex by using force or threatening to harm you or someone close to you? Just so there is no mistake, by sex we mean putting a penis in your vagina.” In order to help estimate whether pregnancy was a result of a specific rape encounter, women aged 12-45, who had been sexually assaulted one time only were included in the analysis. Among the 405 women who were eligible for inclusion in the study, 26 reported a pregnancy post rape. When accounting for likely use of hormonal contraceptives, it was estimated that the overall per-incident rape-pregnancy would be 7.98\%. Consensual per-incident pregnancy rates in women (who were aged 21-42) have been placed between 2-4\% (e.g. Wilcox et al. 2001). This study suggests that per-incident rapepregnancy rates are more likely than consensual pregnancies, suggesting rape may give an evolutionary advantage to males who desire to spread their genetic makeup.

\section{Animal Adaptations to Rape}

Humans are not the only species in which rape occurs. It has been found that male bottlenose dolphins will work collectively in order to intimidate a female and force her into engaging with intercourse (Connor, Smoker \& Richards, 1992). It is believed that rape occurs in animal species for the 
same reasons as it does in humans, where it is a reproductive tactic to allow males to have a higher chance of successful reproduction (e.g. Apostolou, 2013; Cox \& Le Beouf, 1977; Gowaty \& Buschhaus, 1998). Additionally, there is evidence to suggest that drake ducks have evolved to allow them to engage in forced copulation (Brennan, Clark \& Prum, 2010). Drake penises have evolved to extend in an anti-clockwise motion up to $20 \mathrm{~cm}$ in less than half a second, and have backward pointing spikes that enable them to stay attached to a female. They also have soft 'dusters' which allow the removal of other drake's sperm.

Therefore, there is evidence that may suggest that rape has evolved as a reproductive tactic in humans, as well as in some animal species (e.g. Palmer, 1989; Smuts \& Smuts, 1993; Thornhill, 1980; Thornhill \& Thornhill, 1987). However, regardless of the reasons for rape, rape is undoubtedly costly. Rape can be argued to be particularly costly to females due to the chance of conception with an undesired mate. As sexual assault is highly detrimental on a number of levels, women may have evolved counter adaptions to rape that are inherited in later generations.

For example, despite the apparent adaptation in drakes which may help to increase the rate of reproduction, only 3\% of these forced copulations results in fertilisation (Burns, Cheng \& McKinney, 1980). It is therefore possible that female ducks have evolved their own counter-adaptations to reduce the risk of pregnancy from unwanted copulation. One such counter-adaptation comes from the clockwise direction in which a duck's vagina spirals. Brennan et al., (2007) found that a drake could project its penis into a straight test tube, or one that spirals anti-clockwise with ease. However, it was much more difficult to insert into a tube that spiralled clockwise, in the same way that a duck's vagina does. This creates great difficulty for forced copulation for the drake, and suggests that rape as an evolutionary tactic and counter-adaptations to rape go across species. There is also evidence suggestive of female counter-adaptations to rape in water beetles (Bergsten \& Miller, 2005), waterstriders (Arnqvist \& Rowe, 1995; Rowe, Arnqvist, Sih \& Krupa, 1994; Watson, Stallman \& Arnqvist, 1998), and scorpion flies (Thornhill, 1980, 1984; Thornhill \& Sauer 1991). However, extrapolation from research on animals to suggest the evolution of a rape adaptation in humans has been criticised (e.g., Coyne, 2003). As such, to be able to suggest the evolution of a female counteradaptation to rape, it is also necessary to look at research on humans.

\section{Counter-Adaption Rape Behaviour}

As well as evidence of female counter-adaptations to rape in animal species, there is evidence to suggest that women may have evolved mechanisms to reduce the likelihood of rape. It is important to note that considering evolutionary perspectives of rape and women's avoidance of rape in no way justifies this terrible crime, and certainly does not shift the blame to victims. Rather, the purpose of this chapter is to provide an overview of the evidence that has been put forward as support for the hypothesis that women may have evolved a counter-adaptation to rape that allows them maintain their reproductive success and overall fitness. For example, it has been suggested that women appear to behave in certain ways that may reduce their risk of rape. The Rape Avoidance Inventory (RAI; McKibbin et al. 2009 details behaviours women report they would perform to avoid rape. These behaviours fell into 4 broad categories; avoid strange men, avoid appearing sexually receptive, avoid being alone, be aware of surroundings/defensive preparedness. Therefore, there appears to be common behaviours that women engage in in order to potentially reduce the risk of rape.

The Bodyguard Hypothesis (Wilson \& Mesnick, 1997) 
As well as adopting certain behaviours which may contribute to the avoidance of situations that could result in a rape, it has also been suggested that women have evolved preferences mates and male friends who can protect them, known as the bodyguard hypothesis (Wilson \& Mesnick, 1997), This hypothesis proposes that women choose to surround themselves with mates and male friends who are likely to be able to offer protection, through being physically formidable and strong, particularly in high risk places (e.g. in a nightclub or walking at night). Women may choose to surround themselves with strong or intimidating looking males to either intimidate or act as protectors towards potential attackers. Similarly, it is suggested that women form alliances with other females (Smuts \& Smuts, 1993), which may be due to the idea of 'strength in numbers'. However, it is also possible that women may surround themselves with formidable mates and friends because, on average, they are physically weaker compared to men and thus want physical protection in general, rather than specifically as a counter-adaptation to rape. Indeed, women's fear of crime in general is associated with preferences for physically formidable and dominant mates (e.g., Snyder et al. 2011; Ryder, Maltby, Rai, Jones \& Flowe, 2016), which may suggest desire for protection is associated with vulnerability more generally, rather than as a mechanism to prevent rape specifically.

\section{Hormonal influences on female counter-adaptations to rape}

There appear to be hormonal influences on women's counter-adaptations to rape. Although rape is always traumatising and carries a high cost, there are some situations in which counter-adaptive rape behaviours are also costly to a female as they limit the chances of finding a suitable mate. In order to balance this, it may be that counter-adaptations to rape are particularly active when the costs of rape are considered to be higher, such as when rape is most likely to result in an unwanted pregnancy. Chance of conception ranges from approximately $9 \%$ at peak fertility, compared to zero chance in early follicular phases (Wilcox et al. 2001). Therefore, although the costs of rape are always high, rape that has a high chance of unwanted conception can be argued to be relatively more harmful to a female's fitness. It may, therefore, be the case that rape avoidance mechanisms are particularly active during ovulation, the phase of the menstrual cycle during which conception is most possible.

Female mate choice is argued to be of primary importance, particularly during the phase of peak fertility, known as the cycle shift hypothesis (Gangestad \& Thornhill, 1998). A woman's choice of mate is closely related to increasing the chance of reproduction with a male who has strong genetics. In order to increase the chances of reproducing with a male with quality genetics, women find masculine features attractive when they are ovulating compared to the rest of their cycle. For example, whilst ovulating females find masculine symmetric faces more physically attractive (PentonVoak, Perrett \& Castles, 1999; Penton-Voak \& Perrett, 2000; Johnston, Hagel, Franklin, Fink \& Grammer, 2001). At peak fertility, women have been shown to prefer taller men (Pawlowski \& JasienSka, 2005) who have higher testosterone levels (Roney \& Simmons, 2008). In contrast, women appear to have stable preferences for traits that indicate that a man will likely be a long-term partner who will provide for offspring (e.g., Gangestad, Simpson, Cousins, Garver-Apgar \& Christianson, 2004). Rape takes away this choice from women, and so is particularly costly especially in regards to unwanted conception.

In brief, the average menstrual cycle lasts from 28-35 days (Nillni, Toufexis \& Rohan, 2011). The follicular phase begins on day 1 of menstruation (which on average will last around 5 days) and ends on either day 14 or 15 when ovulation begins. At this point, fertility is highest for women. After this, the luteal phase begins and will usually last until day 28, or until menstruation begins again. Therefore, in summary, conception risk fluctuates over the menstrual cycle, and is highest during the ovulatory phase (Wilcox et al. 2001). Although rape is always traumatising and costly, regardless of menstural cycle phase, there may be trade-offs associated with rape avoidance behaviours. 
That is, it could be costly to consistently behave in a way to avoid rape. For example, avoidance of situations of increased risk of rape, such as not going out late at night, could hinder mate-seeking opportunities and chances of attracting a potential mate. Therefore, mechanisms that may be associated with a female counter adaptation to rape may be particularly prominent when the benefits of these provisions outweigh any costs. Fessler (2003) argues that mechanisms that influence women's rape avoidance behaviours should coincide with women's conception risk. Evidence will now be reviewed in support of this theory.

\section{Risk avoidance over the menstrual cycle}

In order to decrease the likelihood of rape during ovulation, it is thought that women will avoid 'high risk' situations that increase their risk of rape during the fertile phase of the menstrual cycle. These situations generally include ones in which a woman is alone and vulnerable to an attack by a predatory male.

Research investigating female counter-adaptations to rape across the menstrual cycle was first conducted by Chavanne and Gallup (1998). They tested whether women who were in the ovulatory phase compared to other phases of the menstrual cycle would report having engaged in fewer behaviours that would increase their risk of rape (e.g. letting a stranger into their home, walking in dimly lit areas, going to church). They presented women with a checklist of activities and asked them to indicate the activities that they had participated in during the past 24 hours. Participants' current menstrual cycle phase was measured using the forward count method (Grammar, 1993), which entails estimating the ovulatory window based on the date of a woman's last menstrual period. Further, each activity had an associated numerical 'risk' score, as determined by ratings of rape risk that had been given by a separate group of participants. The activities, thus, could be grouped into high, medium, and low rape risk categories. It was found that naturally cycling women reported having engaged in fewer high risk behaviours if they were in the fertile phase compared to their non-fertile phase of their menstrual cycle. Additionally, women who were using hormone-based contraception had no significant fluctuation across their cycle with respect to risk taking behaviour. These results suggest that avoidance of rape-specific risk behaviours may be specific to ovulation when perceived costs of rape may be at their highest and overshadow the benefits of situations where a suitable mate may be found.

However, Chavanne and Gallup’s (1998) methodology has been critiqued (e.g., Bröder \& Hohmann, 2003; McKibbin et al, 2008). For example, the validity of the rape risk measurement has been called into question. For instance, women who had engaged in several low risk activities (e.g. staying home to watch a film) could still have an overall risk taking score similar to women who had engaged in a few highly risky activities (e.g., walking home at night down a poorly lit street). In addition, the forward counting method of determining cycle phase is generally considered to be unreliable and inaccurate, particularly when relying on retrospective memories of participants (Bröder \& Hohmann, 2003). A backward counting approach is preferable; here, participants contact the experimenter on the date when their period begins, and the experimenter can count backwards from that date to determine the ovulatory window. Another limitation is that changes in risk taking behavior as a function of menstrual cycle phase were examined between rather than within subjects. For reasons that have nothing to do with fertility, it is possible that ovulating women as a group were on average more risk-adverse compared to their non-fertile counterparts. This made it difficult to understand whether overall, risk taking behaviours truly fluctuated, and thus, in view of these limitations, replication was warranted.

Bröder and Hohmann (2003) sought to replicate Chavanne and Gallup (2003), refining the risk taking measure. A group of male and female participants rated the riskiness of a range of activities. 
The 20 highest rated activities were considered risky (e.g., walking alone in a park) and the lowest were considered non-risky (e.g., speaking on the phone to a friend). Menstrual cycle phase was measured within-subjects, and women reported their risk taking during different points of their menstrual cycle. The researchers estimated the stage of menstrual cycle through using both the forward and backward cycling method. They replicated Chavanne and Gallup’s (1998) findings. Risky behaviours were found to decrease during ovulation, while the frequency of engaging in non-risky behaviours remained constant across the cycle. Thus, the reduction risky behaviour cannot be accounted for by a general reduction in activity. However, both Bröder and Hohmann's (2003) and Chavanne and Gallup's (1998) research was based solely on self-report. Self-reports of behaviours may also be inaccurate due to retrospective remembering of activities and responding in a socially desirable way. Women may be hesitant to report instances wherein they went out alone, or on a date, for example. Furthermore, risk behaviours in the checklists were limited too instances of stranger rape, without consideration of acquaintance rape, despite being more common (Office for National Statistics, 2013).

Both of these studies are widely reported when discussing adaptations to rape, as they support the bold claim that women avoid situations that heighten their risk of rape, particularly during peak fertility. However, risk behaviours, such as going out alone late at night, could potentially increase one's risk of rape, but at the same time, they also could potentially increase one's chances of meeting a desirable mate. Therefore, perhaps there are mechanisms that allow women to establish when to engage in high risk behaviour. Further, perhaps there are other behaviours and cognitions that vary across the menstrual cycle to allow women to control their risk of rape. We will now turn to reviewing these.

\section{Increased strength}

Theoretically, increased physical strength is one possible way in which women may counter their risk of rape. In unwanted sexual scenarios, this would be advantageous as it would allow them to potentially fend off an attacker and avoid rape. Thus, given the high evolutionary cost of rape, increased strength during ovulation may have evolved as a counter-adaptation to rape in women.

To test this hypothesis, Petralia and Gallup (2002) tested whether fertility status influenced strength by gauging women's reactions to sexual assault in relation to their menstrual cycle phase. Women of reproductive age completed a handgrip test in order to obtain a baseline strength level. After this, they completed a questionnaire regarding the regularity of their menstrual cycle. Participants were then exposed to one of two brief scenarios. The control scenario described a women walking to her car in broad daylight in the presence of other people. The sexual assault scenario described a woman walking to her car late at night through a forest whilst being followed by an unknown man. The scenario ends with the woman beginning to unlock her car door and feeling the unknown man's hand on her shoulder. Participants then carried out two further handgrip and reaction time tasks whilst being asked to consider the scenario that they had read. Finally, the participants used a urinebased test to aid to estimate menstrual cycle phase.

It was found that there was no difference in baseline handgrip strength as a function of menstrual cycle phase. However, participants who were ovulating and had been exposed to the sexual assault scenario were had stronger post treatment handgrip strength when compared to ovulating women who were exposed to the control scenario. All other groups (i.e., women during phases of lower conception risk or who were using hormonal contraceptives) exhibited a decrease in handgrip strength following the scenario, regardless of which scenario to which they were exposed. Taken together, these results suggest that women's counter-adaptations to rape can be captured in physiology, and appear to be most active during ovulation, when the reproductive costs of rape are highest. 
Petralia and Gallup (2002) hypothesised that as women in their ovulatory phase are less likely to be raped (Morgan, 1981, as cited in Petralia and Gallup, 2002, though see Fessler 2003), there may be a connection between increased strength and rape avoidance. However, other research has suggested that rape is not less frequent during ovulation (Fessler, 2003), or may even be more likely (Beirne et al. 2011). While Petralia and Gallup (2002) suggested that this finding is representative of the increased ability to thwart off a sexual attack when it would have the most reproductive costs, it is not entirely clear what increased handgrip strength in response to the likelihood of sexual assault occurring was operationalising. Moreover, while their sexual assault scenario was suggestive of rape, participants may have alternatively thought that the scenario would end in a physical assault or robbery. It may be the case that women increase their risk aversion more generally during ovulation to maximise reproductive success.

\section{Avoidance of potentially threatening males}

Other behavioural evidence that women's counter-adaptation to rape may be particularly active during the phase of peak fertility is that of Guéguen (2012a), who examined women's avoidance of 'strange looking' men. Participants were led to believe they would be participating in a lexical decision task, and were asked to take a seat in a waiting room. Participants placed a labial band strip on their tongue, which they believed was to measure cortisol levels. Unbeknownst to the participants, the labial band measured levels of luteinising hormone in order to determine menstrual cycle phase. A male confederate, who had been manipulated to appear 'shady looking' was also in the waiting room. The investigators were actually interested in determining the location in which women sat while they were waiting. It was found that ovulating women sat significantly further away from the 'suspicious looking male' than women who were not ovulating. The investigators concluded that women are more avoidant of 'dangerous looking' men around ovulation. This may be indicative of a counter-adaptation to rape. However, there was no control condition wherein male confederate who did not 'shady' looking was present in the waiting room. Therefore, it is unknown whether fertile women were avoiding the man specifically because of his appearance.

\section{Evaluation of potential for coercion}

Other researchers have also shown evidence that women may perceive men differently according to their fertility status. One particular counteradaptation to rape that would be advantageous would be an increased ability to detect the potential for sexual coercion early in an encounter with a man. By so doing, women may be more accurate at detecting a man's actual desires, and therefore, will be better able to avoid men who may pose a threat to their fitness. To test this hypothesis, GarverApgar, Gangestad and Simpson (2007) conducted an experiment to test women's perceptions of different types of men as a function of ovulatory status, which was measured within subjects. They found that women were much more accurate in detecting sexual coercion whilst ovulating. Furthermore, when participants believed a man to be suspicious, they were likely to overestimate the level of danger he posed to them. Women reported that this strategy enabled them to maximize their ability to avoid dangerous men. Garver-Apgar et al (2007) suggest that a cognitive error management bias (See Haselton, Nettle \& Andrews, 2005) may be the cause of these over estimations. It is less costly to overestimate the likelihood of coercion than to underestimate it.

However, rather than relating to a counter adaptation to rape specifically, Garver-Apgar et al. (2007) have argued that their results may reflect a general increase in fear mid-cycle. Although fear and anxiety appear to be greater during the luteal phase (Solis-Oritz \& Cabrera, 2002; Vandermolen, Merckelbach, \& Vandenhout, 1988), or there may even be a dip in anxiety mid-cycle 
(Gottschalk, Kaplan, Gleser Winget, 1961), previous research does show enhanced sensitivity to fear during ovulation (Pearson \& Lewis, 2005). Therefore, these findings may reflect an increase in risk perception or fear more generally during ovulation, rather than the counter adaptation to rape being particularly active during ovulation.

\section{Outgroup evaluation}

Women may also differentially avoid outgroup members depending on fertility status. Navarrete and colleages (Navarrete, Fessler, Fleischmann and Geyer, 2009; McDonald, Asher, Kerr \& Navarrete, 2011) studied bias towards outgroup members over the menstrual cycle. Outgroup members may have been considered threatening in evolutionary history (Daly \& Wilson, 1988, as cited in Navarrete et al. 2009), possibly due to the lack of social controls that may be inherent in ingroup members. Navarrete et al. (2009) examined attitudes and ratings of attractiveness and 'scariness' of outgroup members (as defined by being of a different race) across the menstrual cycle. Women showed higher racial bias, as measured by higher fear and decreased attraction of outgroup members during the phase of peak fertility. McDonald et al (2011) showed the bias towards outgroup members during ovulation extended beyond race using an implicit associated test. These findings therefore suggest that women may have a psychological mechanism that increased bias towards men who may be considered threatening with regards to conforming to social norms, and thus may be associated with an increased risk of sexual assault, with the bias being emphasized during peak fertility when the costs of rape are arguably the highest. This could be considered as evidence for a counter-adaptation to rape in females, with the mechanism being influenced by hormones.

However, some researchers have suggested that women may be more attracted to outgroup members during peak fertility as a way to increase genetic heterogeneity in offspring (e.g., Marlowe, 2004; Roberts \& Little, 2008), which appears contradictory to the findings of Navarette et al (2009). Navarette and colleagues (2009) suggest further research is necessary to understand the coercionavoidance versus heterogeneity-attraction processes.

\section{Directions for future research}

Evidence appears to suggest that women, and some female animals, may have evolved counteradaptations to rape. Moreover, mechanisms associated with a counter-adaptation to rape in women appear to be particularly active during the phase of peak fertility, which may be due to the relatively higher costs of rape when conception is most possible. For example, women behave in a way that may help to decrease their risk of encountering a sexually aggressive man. However, some research regarding women's behaviour over the menstrual cycle may appear contradictory to a female counter-adaptation to rape, and women may behave in ways that could put themselves at greater risk of encountering a sexually aggressive male during ovulation. It is important to note that exploration of the association between menstrual cycle phase and risk of sexual assault in no way justifies violence against women, and it does not shift the blame to the victims.

For example, ovulating women have been shown to have an increased desire to attend social events where they are more likely to meet men (e.g., a singles mixer, Haselton \& Gangestad, 2006). Additionally, research has shown that in order to increase the likelihood of attracting a mate, ovulating women are more likely to dress in a provocative manner (Durante, Li \& Haselton, 2008) and use a higher amount of cosmetics for these types of events (Guéguen, 2012c) and walk more sexily (Guéguen, 2012b). Partnered women become more partial to having sex with unfamiliar men (Gangestad, Thornhill \& Garver-Apgar, 2005), and respond favourably to romantic gestures from male strangers (Guéguen, 2009a; 2009b) during ovulation. Ovulating women were significantly 
more likely to give their number to (Guéguen, 2009a) and dance with a male confederate (Guéguen, 2009b), despite having never met him before. Such situations could increase the chance of encountering a sexual aggressive male, and seem to contradict the suggestion that women have evolved a mechanism that works to decrease the risk of rape. Ellsworth and Palmer (2010) have called for greater precision in testing the relationship between adaptations designed to seek good quality mates at peak fertility whilst balancing the costs of rape.

Counter-adaptations to rape need to involve assessing the type of male to which they are interacting with, and thus involve complex, but sophisticated mechanisms. In humans, a cognitive error bias may offer a reason as to why women may feel comfortable with strange men in some situations (e.g., Gueguen 2009a; 2009b) and not others (e.g., Gueguen, 2012). For example, a nightclub (e.g., Geguen, 2009) is a social place with bouncers who are there to ensure all event goers are safe throughout the night. Women in this context may, therefore, be more accepting towards a strange man who approaches her and will more accurately judge their sexual coercion. However, a woman could meet the same man down a long dark alley, and overestimate the danger posed by the man, and may consider him to be suspicious due to an environment which may feel less safe. Alternatively, the reason may be due to the appearance of the man. In Gueguen (2012), the male confederate was manipulated to appear 'shady' and therefore the further distance that ovulating women sat may be avoidance of a potentially threatening male in line with a female counter-adaptation to rape. On the other hand, the male confederates to which ovulating women responded favorably to a romantic gesture from in Gueguen's earlier research (Gueguen, 2009a; 2009b) were chosen for their attractiveness. Similarly, while ovulating women showed a desire to dress more provocatively, this was in response to being told they would meet single, attractive males at the event. Furthermore, whilst Flowe, Swords and Rockey (2012) found women to show increased engagement with a male during their ovulatory phase, this was only true if the male appeared masculine. In contrast, engagement in nonverbal behaviour was relatively lower in ovulating women when the male appeared 'shady' (2012). This may represent the fact that women's behaviour has the highest reproductive consequences at peak fertility they must balance the goals of behaving in a way to both benefit reproductive fitness (e.g., seeking a quality mate) with preventing costs to reproductive fitness (e.g., rape). Future research examining the relationship between attraction versus avoidance of certain males during peak fertility should consider the appearance of the man and setting. For example, having a control condition in Guéguen's (2012a) study wherein there was a male who was manipulated to appear attractive, or neutral, in addition to the condition with the 'shady looking' male, may have allowed an understanding of women's avoidance behaviours over the menstrual cycle.

\section{Are avoidance behaviours specific to rape, or risk more generally?}

Women's avoidance of situations of increased risk of rape may simply reflect danger avoidance more generally rather a female counter-adaptation to rape specifically. That is, it is not known from previous research whether women are avoiding rape specifically, or are avoidant of all danger and risk in a more general sense, particularly at peak fertility. It is possible that females may be more receptive to any type of danger during ovulation in order to protect their fertility in general. For example, in Petralia and Gallup's (2002) study on female strength and ovulation in response to risk of sexual assault, the sexual assault scenario did not specifically state that a sexual assault was about to occur and instead left it to the imagination of the female participant. Some participants may, therefore, have thought the scenario was suggesting that a robbery, car jacking, or a physical assault was going to occur. Additionally, the questionnaires used by both Bröder and Hohmann, and Chavanne and Gallup did not specifically refer to behaviours specific sexual assault. Although behaviours that are commonly linked to sexual assault appeared on the questionnaires (e.g. walking in dimly lit areas), these behaviours are also closely related to other crime and danger more generally. Therefore, it 
is unclear whether a risk-averse response from female participants is directly linked to rapeavoidance, or avoidance of danger.

Garver-Apgar et al., (2007) examined domain specificity in women's perception of male traits over the menstrual cycle, and reported that women were more attuned to sexual coercion when ovulating in comparison to other male traits outside of fluctuations in risk avoidance. However, the factors that were assessed as a measure of 'sexual coercion' (e.g., creepiness) may also correspond to dangerous males in general. Moreover, bias towards outgroup members (e.g., Navarrete et al. 2009) suggests wariness of potentially threatening men, rather than males who are likely to rape specifically.

In support of the mechanism being domain general over domain specific, there is evidence suggesting that females engage in risk avoidance behaviours during ovulation in situations that are not sexual. Kaighobadi and Stevens (2013) studied the effects of ovulation and risk taking behaviours in women who were gambling. It was found that ovulating women would engage in less impulsive behaviour when shown pictures of attractive men whilst gambling. However, impulsivity did not change when shown a picture of attractive landscapes, or in non-fertile females. Women have also been shown to take less risks in an investment task when ovulating and working with strangers (Ball et al., 2013). Furthermore, females may have an increased response to threatening images in general, and have been found to have enhanced detection of faces showing fear (Pearson \& Lewis, 2005). Similarly, there is neural evidence to suggest that the way in which women process risk may different depending on their phase of the menstrual cycle. When fertile, women showed increased activation in brain areas associated with risk evaluation when being shown images of typically masculine males, which may be considered a threat compared to non-fertile women (Rupp et al., 2009). Finally, Šukolová and Sarmány-Schuller (2011) also found that women perceive risk differently according to their fertility status, regardless of what the risk was. It may therefore be that women are more perceptive to risk in general during ovulation, rather than it being an evolutionary adaptation which is specific to rape avoidance.

Taken together, there is evidence to suggest that risky behaviours may be lessened during ovulation in a more general sense, rather than specifically in response to rape. Therefore, evidence suggestive that there is a counter-adaptation to rape, may not apply specifically to women's rape avoidance, but rather their avoidance of risk more generally. Future research should focus on testing for domain specificity through assessing women's responses to the physical versus sexual costs of rape, for example, or through assessing risk aversion over the menstrual cycle more generally. However, researchers should consider the assumptions of the shadow of sexual assault hypothesis (Ferraro, 1995; 1996; Warr, 1985) when designing research into female counter adaptations to rape. This hypothesis proposes that women's disproportionate fear of crime in relation to men's and their risk of victimization is due to the assumption that any crime could potentially escalate into a sexual crime. That is, that due to the higher costs (e.g. risk of unwanted conception), women's fear of sexual assault will 'shadow' their fear of encountering other types of crime (e.g. robbery). Therefore, it could be difficult to distinguish whether responses are specific to risk of rape, or danger more generally. One suggestion for future research is to assess women's responses to risk, and how they vary over the menstrual cycle, in response to danger whilst controlling for the risk of rape, such as by assessing responses to female-perpetrated crimes. To be able to conclude that ovulatory declines in risky behaviour represent an evolved rape-avoidance adaptation to prevent pregnancy resulting from rape, evidence showing "special design" for performing a specific function which cannot be explained with other accounts is necessary (Andrews et al. 2002; Thornhill, 1990d; 1997).

\section{Summary and conclusion}


In summary, women appear to behave in ways that could be suggestive of a female counteradaptation to rape. For example, female animals have specialized physiology that may prevent forced copulation from males (e.g., Brennan et al. 2007; Bergsten \& Miller, 2005; Arnqvist \& Rowe, 1995; Rowe, Arnqvist, Sih \& Krupa, 1994; Watson, Stallman \& Arnqvist, 1998; Thornhill, 1980, 1984; Thornhill \& Sauer 1991). Women also appear to have mechanisms that may be indicative of evolved adaptive traits that could help to reduce the risk of rape, such as avoidance of situations of increased risk of rape (McKibbin et al. 2009) and a preference for mates and male friends who may be able to offer protection (Wilson \& Mesnick, 1997). What is more, mechanisms that may help to prevent rape appear most active during the phase of peak fertility, when rape arguably poses the highest costs to fitness. For example, during ovulation, women are more avoidant of situations of increased risk of rape (e.g., Chavanne \& Gallup, 1998; Bröder \& Hohmann, 2003), show increased strength in response to a scenario suggestive of sexual assault (Petralia \& Gallup, 2002), over-estimate male's sexual coercion (Garver-Apgar et al. 2007), show bias towards outgroup members (Navarette et al. 2009; McDonald et al. 2011); and keep further distance from a male manipulated to appear 'shady' (Guéguen, 2012a). Taken together, these findings appear to support a female counter-adaptation to rape, which is particularly active when conception risk would be highest. However, much of this research is based on self-reports of behaviour, which may be inaccurate due to retrospective reporting and errors in remembering, and socially desirable responding on surveys. Moreover, research also suggests that women behave in ways that could potentially increase their chances of encountering a sexually aggressive male (e.g., Guéguen 2009a; 2009b; Durante et al. 2008; Gangestad et al. 2005). Therefore, future research should focus on refining the relationship between balancing mechanisms designed to seek good quality mates at peak fertility and avoiding situations that could potentially be associated with increased risk of rape, with a preferential focus on behavioural, as opposed to self-report methods. Secondly, future research should consider assessing whether the mechanisms as reviewed above are specific to a female counter-adaptation to rape, or work to protect women from all harm more generally by assessing women's responses to the risk more generally over the menstrual cycle.

\section{References}

Andrews, P. W., Gangestad, S. W., \& Matthews, D. (2002). Adaptationism-how to carry out an exaptationist program. Behavioral and Brain Sciences, 25(4), 489-504.

Apostolou, M. (2013). The evolution of rape: The fitness benefits and costs of a forced-sex mating strategy in an evolutionary context. Aggression and Violent Behavior, 18(5), 484-490.

Arnqvist, G., \& L. Rowe. (1995). Sexual conflicts and arms races between the sexes: A morphological adaptation for control of mating in a female insect. Proceedings of the Royal Society of London B, 261, 123- 127

Ball, A., Wolf, C. C., Ocklenburg, S., Herrmann, B. L., Pinnow, M., Brüne, M., Wolf O. T., \& Güntürkün, O. (2013). Variability in ratings of trustworthiness across the menstrual cycle. Biological Psychology, 93(1), 52-57.

Bateman, A. J. (1948). Intra-sexual selection in Drosophila. Heredity, 2, 349-368.

Beirne, P., Hall, J., Grills, C., \& Moore, T. (2011). Female hormone influences on sexual assaults in Northern Ireland from 2002 to 2009. Journal of Forensic and Legal Medicine, 18(7), 313316.

Brennan, P. L., Clark, C. J., \& Prum, R. O. (2010). Explosive eversion and functional morphology of the duck penis supports sexual conflict in waterfowl genitalia. Proceedings of the Royal Society of London B: Biological Sciences, 277(1686), 1309-1314.

Brennan, P. L., Prum, R. O., McCracken, K. G., Sorenson, M. D., Wilson, R. E., \& Birkhead, T. R. (2007). Coevolution of male and female genital morphology in waterfowl. PLoS one, 2(5), e418. 
Bröder, A., \& Hohmann, N. (2003). Variations in risk taking behavior over the menstrual cycle: An improved replication. Evolution and Human Behavior, 24(6), 391-398.

Burns, J. T., Cheng, K. M., \& McKinney, F. (1980). Forced copulation in captive mallards. I. Fertilization of eggs. The Auk, 97(4), 875-879.

Chavanne, T. J., \& Gallup Jr, G. G. (1998). Variation in risk taking behavior among female college students as a function of the menstrual cycle. Evolution and Human Behavior, 19(1), 27-32.

Clark, A. (1987). Women's Silence, Men's Violence. London: Pandora Press.

Confer, J. C., Easton, J. A., Fleischman, D. S., Goetz, C. D., Lewis, D. M., Perilloux, C., \& Buss, D. M. (2010). Evolutionary psychology: Controversies, questions, prospects, and limitations. American Psychologist, 65(2), 110-126.

Connor, R. C., Smolker, R. A., \& Richards, A. F. (1992). Two levels of alliance formation among male bottlenose dolphins (Tursiops sp.). Proceedings of the National Academy of Sciences, 89(3), 987-990.

Cox, C. R., \& Le Boeuf, B. J. (1977). Female incitation of male competition: a mechanism in sexual selection. American Naturalist, 317-335.

Coyne, J. A. (2003). Of vice and men: A case study in evolutionary psychology. In C. B. Travis (Ed.), Evolution, gender, and rape (pp. 176-190). Cambridge, Massachusets, MIT Press.

Department of Justice (2012). An updated definition of rape. Retried 29/11/2016 from https://www.justice.gov/opa/blog/updated-definition-rape

Durante, K. M., Li, N. P., \& Haselton, M. G. (2008). Changes in women's choice of dress across the ovulatory cycle: Naturalistic and laboratory task-based evidence. Personality and Social Psychology Bulletin, 34, 1451-1460.

Eisenhower, MS. (1969). To Establish Justice, To Insure Domestic Tranquility. Final Report of the National Commission on Cause and Prevention of Violence. December, U.S. Government Printing Office, Washington.

Ellsworth, R. M., \& Palmer, C. T. (2011). The Search for Human Rape and Anti-Rape Adaptations: Ten Years after A Natural History of Rape. In K. M Beaver \& A. Walsh (Eds.). The Ashgate Research Companion to Biosocial Theories of Crime (pp. 349-368). Surrey, England: Ashgate publishing company

Epstein, J., \& S. Langenbahn. (1994). The Criminal Justice and Community Response to Rape. Contract No. OJP-9-C-009. Washington DC: National Institute of Justice.

Ferraro, K. F. (1995). Fear of crime: Interpreting victimization risk. Albany, NY: State University of New York Press.

Ferraro, K. F. (1996). Women's fear of victimization: Shadow of sexual assault? Social Forces, 75(2), 667-690.

Fessler, D. M. (2003). Rape is not less frequent during the ovulatory phase of the menstrual cycle. Sexualities, Evolution \& Gender, 5(3), 127-147.

Flowe, H. D., Swords, E., \& Rockey, J. C. (2012). Women's behavioural engagement with a masculine male heightens during the fertile window: evidence for the cycle shift hypothesis. Evolution and Human Behavior, 33(4), 285-290.

Gangestad, S. W., \& Thornhill, R. (1998). Menstrual cycle variation in women's preferences for the scent of symmetrical men. Proceedings of the Royal Society of London B: Biological Sciences, 265(1399), 927-933.

Gangestad, S. W., Thornhill, R., \& Garver-Apgar, C. E. (2005). Women's sexual interests across the ovulatory cycle depend on primary partner developmental instability. Proceedings of the Royal Society of London B: Biological Sciences, 272(1576), 2023-2027.

Gangestad, S.W., Simpson, J.A., Cousins, A.J., Garver-Apgar, C.E., \& Christensen, P.N. (2004). Women's preferences for male behavioural displays change across the menstrual cycle. Psychological Science, 15, 203-207. 
Garver-Apgar, C.E., Gangestad, S.W., \& Simpson, J. (2007). Women’s perceptions of men’s sexual coerciveness change across the menstrual cycle. Acta Psychologica Sinica, 23, 536-540.

Gottschalk, L. A., Kaplan, S. M., Gleser, G. C., \& Winget, C. M. (1962). Variations in magnitude of emotion: a method applied to anxiety and hostility during phases of the menstrual cycle. Psychosomatic Medicine, 24(3), 300-311.

Gottschall, J.A., \& Gottschall, T.A. (2003). Are per-incident rape-pregnancy rates higher than perincident consensual pregnancy rates? Human Nature, 14, 1-20.

Gowaty, P. A., \& Buschhaus, N. (1998). Ultimate causation of aggressive and forced copulation in birds: female resistance, the CODE hypothesis, and social monogamy. American Zoologist, 38, 207-225.

Grammar, K. (1993). 5- $\alpha$-androst-16en-3 $\alpha$-on: a male pheromone? A brief report. Ethology and Sociobiology, 14, 201-208.

Grubb, A., \& Turner, E. (2012). Attribution of blame in rape cases: A review of the impact of rape myth acceptance, gender role conformity and substance use on victim blaming. Aggression and Violent Behavior, 17(5), 443-452.

Guéguen, N. (2009a). The receptivity of women to courtship solicitation across the menstrual cycle: A field experiment. Biological Psychology, 80, 321-324.

Guéguen, N. (2009b). Menstrual cycle phases and female receptivity to a courtship solicitation: An evaluation in a nightclub. Evolution and Human Behavior, 30, 351-355.

Guéguen, N. (2012a). Risk Taking and Women’s Menstrual Cycle: Near Ovulation, Women Avoid a Doubtful Man. Letters on Evolutionary Behavioural Science, 3, 1-3.

Guéguen, N. (2012b). Gait and menstrual cycle: ovulating women use sexier gaits and walk slowly ahead of men. Gait Posture, 35(4), 621-624.

Guéguen, N. (2012c). Makeup and menstrual cycle: Near ovulation, women use more cosmetics. The Psychological Record, 62(3), 541-548.

Haselton, M. G., \& Gangestad, S.W. (2006). Conditional expression of women's desires and men's mate guarding across the ovulatory cycle. Hormones and Behavior, 49, 509-518.

Haselton, M. G., Nettle, D. \& Andrews, P.W. (2005). The evolution of cognitive bias. In D. M. Buss (Ed.), Handbook of Evolutionary Psychology (pp. 724-746). Hoboken: Wiley

Johnston, V. S., Hagel, R., Franklin, M., Fink, B. \& Grammer, K. (2001). Male facial attractiveness. Evidence for hormone-mediated adaptive design. Evolution and Human Behavavior, 22, 251-267.

Kaighobadi, F., \& Stevens, J. R. (2013). Does fertility status influence impulsivity and risk taking in human females? Adaptive influences on intertemporal choice and risky decision making. Evolutionary psychology: an International Journal of Evolutionary Approaches to Psychology and Behavior, 11(3), 700-717.

Kilpatrick, D.G., Edmunds, C., \& Seymour, A. (1992). Rape in America: A report to the nation. Charleston, SC: National Victim Center \& the Crime Victims Research and Treatment Center, Medical University of South Carolina.

Marlowe, F. W. (2004). Mate preferences among Hadza hunter-gatherers. Human nature, 15(4), 365-376.

McDonald, M. M., Asher, B. D., Kerr, N. L., \& Navarrete, C. D. (2011). Fertility and intergroup bias in racial and minimal-group contexts evidence for shared architecture. Psychological Science, 22, 860-865.

McKibbin, F., \& Shackelford, K. (2011). Women's avoidance of rape. Aggression and Violent Behavior, 16(5), 437-443.

McKibbin, W. F., Shackelford, T. K., Goetz, A. T., Bates, V. M., Starratt, V. G., \& Miner, E. J. (2009). Development and initial psychometric assessment of the Rape Avoidance Inventory. Personality and Individual Differences, 39, 336-340. 
McKibbin, W.F. (2014). Evolutionary psychology and rape avoidance. In Weekes-Shackelford, V.A., \& Shackelford, T.K. (Eds.), Evolutionary perspectives on human sexual psychology and behavior. New York: Springer.

McKibbin, W.F., Shackelford, T. K., Goetz, A. T., \& Starratt, V. G. (2008). Why do men rape? An evolutionary psychological perspective. Review of General Psychology, 12, 86-97.

Morris, N, M., \& Udry, J, R. (1970). Variations in pedometer activity during the menstrual cycle. Obstetrics and Gynecology, 35, 199-201.

Navarrete, C. D., Fessler, D. M., Fleischman, D. S., \& Geyer, J. (2009). Race bias tracks conception risk across the menstrual cycle. Psychological Science, 20(6), 661-665.

Nillni, Y. I., Toufexis, D. J., \& Rohan, K, J. (2011). Anxiety Sensitvity, the menstrual cycle, and panic disorder: a putative neuroendocrine and psychological interaction. Clinical Psychology Review 31(7), 1183-1191.

Palmer, C. (1989). Is rape a cultural universal? Ethnology, 28, 1-16.

Pawlowski, B., \& Jasienska, G. (2005). Women's preferences for sexual dimorphism in height depend on menstrual cycle phase and expected duration of relationship. Biological Psychology, 70(1), 38-43.

Pawson, E., \& Banks, G. (1993). Rape and fear in a New Zealand city. Area, 25(1), 55-63

Pearson, R., \& Lewis, M. B. (2005). Fear recognition across the menstrual cycle. Hormones and Behavior, 47(3), 267-271.

Pearson, R., \& Lewis, M. B. (2005). Fear recognition across the menstrual cycle. Hormones and Behavior, 47(3), 267-271

Penton-Voak, I. S. \& Perret, D. I. (2000). Female preference for male faces changes cyclically further evidence. Evolution and Human Behavior, 21, 39-48.

Penton-Voak, I. S., Perrett, D. I., \& Castles, D. L. (1999). Menstrual cycle alters face preference. Nature, 399, 741-742.

Petralia, S.M., \& Gallup, G.G., Jr. (2002) Effects of a sexual assault scenario on handgrip strength across the menstrual cycle. Evolution and Human Behaviour 23, 3-10.

Resnick, H. S., Kilpatrick, D. G., Dansky, B. S., Saunders, B. E., \& Best, C. L. (1993). Prevalence of civilian trauma and posttraumatic stress disorder in a representative national sample of women. Journal of Consulting and Clinical Psychology, 61(6), 984-991.

Roberts, S. C., \& Little, A. C. (2008). Good genes, complementary genes and human mate preferences. Genetica, 132(3), 309-321.

Roney, J., \& Simmons, Z. (2008). Women's estradiol predicts preference for facial cues of men's testosterone. Hormones and Behavior, 53, 14-19.

Rowe, L., G. Arnqvist, A. Sih, \& J. Krupa. (1994). Sexual conflict and the evolutionary ecology of mating patterns: Water striders as a model system. Trends in Ecology and Evolution, 9, 289293.

Rupp, H. A., James, T. W., Ketterson, E. D., Sengelaub, D. R., Janssen, E., \& Heiman, J. R. (2009). Neural activation in women in response to masculinized male faces: Mediation by hormones and psychosexual factors. Evolution and Human Behavior, 30(1), 1-10.

Ryder, H., Maltby, J., Rai, L., Jones, P., \& Flowe, H. D. (2016). Women's fear of crime and preference for formidable mates: how specific are the underlying psychological mechanisms?. Evolution and Human Behavior, 37(4), 293-302.

Smuts, B. B., \& Smuts, R. W. (1993). Male aggression and sexual coercion of females in nonhuman primates and other mammals: evidence and theoretical implications. Advances in the Study of Behavior, 22, 1-63.

Snyder, J. K. \& Fessler, D. M. T. (2013a). Reexamining individual differences in women's rape avoidance behaviors. Archives of Sexual Behavior, 42, 543-551. 
Snyder, J. K., Fessler, D. M., Tiokhin, L., Frederick, D. A., Lee, S. W., \& Navarrete, C. D. (2011). Trade-offs in a dangerous world: Women's fear of crime predicts preferences for aggressive and formidable mates. Evolution and Human Behavior, 32(2), 127-137.

Solis-Ortiz, S., \& Cabrera, M. C. (2002). EEG pattern of anxiety along the menstrual cycle. Revisita Mexicana de Psicologia, 19, 187-195.

Šukolová, D., \& Sarmany-Schuller, I. (2011). Fluctuating perception of selected risk situations with respect to hormonal changes during menstrual cycle. Studia Psychologica, 53(1), 3-12.

Symons, D. (1979). The Evolution of Human Sexuality. New York: Oxford University Press.

Thornhill, N. W., \& Thornhill, R. (1991). An evolutionary analysis of psychological pain following human (Homo sapiens) rape: IV. The effect of the nature of the sexual assault. Journal of Comparative Psychology, 105(3), 243-252.

Thornhill, N., \& Thornhill, R. (1990a). Evolutionary analysis of psychological pain of rape victims I: The effects of victim's age and marital status. Ethology and Sociobiology, 11, 155-176.

Thornhill, N., \& Thornhill, R. (1990b). Evolutionary analysis of psychological pain following rape II: The effects of stranger, friend, and family member offenders. Ethology and Sociobiology, 11, 177-193.

Thornhill, N., \& Thornhill, R. (1990c). Evolutionary analysis of psychological pain following rape victims III: The effects of force and violence. Aggressive Behavior, 16, 297-320.

Thornhill, R. (1980). Pape in Panorpa scorpionflies and a general rape hypothesis. Animal Behaviour, 28(1), 52-59.

Thornhill, R. (1984). Fighting and assessment in Harpobittacus scorpionflies. Evolution, 204-214.

Thornhill, R. (1990d). The study of adaptation. In M. Bekoff \& D. Jamieson (Eds.), Interpretation and explanation in the study of behavior (pp 31-62). Boulder, CO: Westview.

Thornhill, R. (1997). The concept of an evolved adaptation. In G. R. Bock and G. Cardew (Eds.). Characterizing human psychological adaptations (pp. 4-22). Chichester: Wiley

Thornhill, R., \& N. Thornhill. (1989). The evolution of psychological pain. In R. W. Bell and N. J. Bell (Eds.) Sociobiology and the Social Sciences (pp. 73-103). Texas Tech University Press.

Thornhill, R., \& Palmer, C. T. (2000). Natural History of Rape: Biological Bases of Sexual Coercion. Cambridge, MA: MIT Press.

Thornhill, R., \& Sauer, K. P. (1991). The notal organ of the scorpionfly (Panorpa vulgaris): an adaptation to coerce mating duration. Behavioral Ecology, 2(2), 156-164.

Thornhill, R., \& Thornhill, N. W. (1987). Human rape: The strengths of the evolutionary perspective. Sociobiology and Psychology: Ideas, Issues, and Applications, 373-400.

Thornhill, R., \& Thornhill, N.W (1983). Human rape: an evolutionary analysis. Ethology and Sociobiology, 4, 137-173.

Tjaden, P., \& Thoennes. (2006). Extent, Nature, and Consequences of Rape Victimization: Findings from the National Violence Against Women Survey. Research Report. Washington, D.C.: U.S. Department of Justice, National Institute of Justice, NCJ 210346.

Trivers, R. L. (1972). Parental investment and sexual selection. In B. Campbell (Ed.). Sexual selection and the descent of man (pp. 136-179). Chicago: Aldine.

Vandermolen, G. M., Merckelbach, H., \& Vandenhout, M. A. (1988). The possible relation of the menstrual-cycle to susceptibility to fear acquisition. Journal of Behavior Therapy and Experimental Psychiatry, 19, 127-133.

Vaughn, A. E. (2002). An evolutionary perspective of human female rape. Unpublished doctoral dissertation. Accessed 03/12/2016 from http://clok.uclan.ac.uk/1747/1/251766.pdf

Warr, M. (1985). Fear of rape among urban women. Social Problems, 32, 238-250.

Watson, P. J., Stallmann, R. R., \& Arnqvist, G. (1998). Sexual conflict and the energetic costs of mating and mate choice in water striders. The American Naturalist, 151(1), 46-58. 
Wilcox, A. J., Dunson, D. B., Weinberg, C. R., Trussell, J., \& Baird, D. D. (2001). Likelihood of conception with a single act of intercourse: providing benchmark rates for assessment of post-coital contraceptives. Contraception, 63(4), 211-215.

Williams, G. C. (1966). Adaptation and natural selection. Princeton, NJ: Princeton University Press Wilson, M., \& Mesnick, S. L. (1997). An empirical test of the bodyguard hypothesis. In P. A. Gowaty (Ed.), Feminism and Evolutionary biology (pp. 505-511). New York: Chapman \& Hall.

Wilson, M., Daly, M., \& Scheib, J. E. (1997). Femicide: an evolutionary psychological perspective. In P. A. Gowaty (Ed.) Feminism and Evolutionary Biology (pp. 431-465). New York: Chapman \& Hall.

World Health Organization, London School of Hygiene and Tropical Medicine, \& South African Medical Research Council. Global and regional estimates of violence against women: Prevalence and health effects of intimate partner violence and non-partner sexual violence. Geneva: World Health Organization; 2013 